\title{
Measurement science summer school in Poznan, Poland
}

Measurement Science in Chemistry Euromaster (MSC) is a consortium of nine European universities that deliver a Master's Degree Programme offering education in the measurement science. The consortium was awarded the ECTNA (European Chemistry Thematic Network Association) Euromaster quality label in 2008. An important activity of the MSC is the summer school, previous ones have been organised in 2008 (Celje, Slovenia), 2009 (Blagoevgrad, Bulgaria) and 2010 (Lepanina, Estonia).

The summer school is an intensive training course of the advanced topics of measurement science in chemistry, e. g. validation of chemical analysis procedures; traceability in chemistry; statistics and statistical basis of calibration; quantification of measurement uncertainty; ISO 17025 quality systems and laboratory assessment; sampling and sample preparation. The teaching methods range from classical lectures to case studies and role playing. Students get follow-up assignments and their learning is evaluated afterwards. The volume of the summer school is 30 ECTS points. Further information is available from the MSC website at http://www.msc-euromaster.eu.

The next summer school will take place from 10 to 23 July 2011 at the University of Poznan in Poland. The summer schools are attended by Master students of the MSC partner universities. For the 2011 edition, a limited number of places are made available to persons who are not en-rolled at one of these universities. The minimum requirement for the qualification of a person enrolling is to have a bachelor degree in chemistry. For details on the summer school contact Danuta Baralkiewicz, danutaba@ amu.edu.pl.

(source: Philip Taylor, EuCheMS newsletter http:// www.euchems.org). 